\title{
Clinical Application and Efficiency Analysis of Shared Decision Making (SDM) in the Treatment of Stable Angina
}

\author{
Hao-Min Cheng ${ }^{1}$, Hsiao-Fen $\mathrm{Hsu}^{2}$, Chih-Yi Lee ${ }^{2}$, Hong- Di Chang ${ }^{2}$, Hsin-Chan Huang ${ }^{2}$, Mei-Jyh Sheu ${ }^{2} \&$ \\ Hsiao-hui $\mathrm{Chiu}^{2,3}$ \\ ${ }^{1}$ Division of Cardiology, Taipei Veterans General Hospital, Taipei, Taiwan \\ 2 Taipei Veterans General Hospital, Taipei, Taiwan \\ ${ }^{3}$ Department of Nursing, National Taipei University of Nursing and Health Sciences, Taipei, Taiwan \\ Correspondence: Hsiao-hui Chiu, Taipei Veterans General Hospital, Taipei, Taiwan, No.201, Sec. 2, Shipai Rd., \\ Beitou District, Taipei City, Taiwan. Tel: 886-2-2871-2121.
}

Received: May 6, 2020

doi:10.20849/ijsn.v5i2.751
Accepted: June 20, 2020

Online Published: June 28, 2020

URL: https://doi.org/10.20849/ijsn.v5i2.751

\begin{abstract}
Background: Cardiac disease is the second leading causes of death in Taiwan in 2018 and coronary artery disease is one of the main reasons.

Aims: The purpose of this study was to estimate whether Shared decision making (SDM) could lower the anxiety of the patient in the treatment of cardiac catheterization and improve the intension of medical decision or not.

Methods: One-group pretest-posttest design.Using the public medical aids opinion questionnaire that was developed by the Taiwan Ministry of Health and Welfare. STROBE guidelines have been adhered to in the reporting of this study.

Results: The anxiety level decrease after the SDM from 3.5 to 2.1 points (p-value $<0.05$ ) and the proportions of the intension to choose medication and surgery increase from $34 \%$ to $66 \%$. Results show that SDM has positive influence in the relief of anxiety.

Conclusion: SDM has positive influence in lowering patient's anxiety and improve the intension of medical decision, the hesitation of patient and deficiency of time are two of the main barriers during the application process.
\end{abstract}

Keywords: patient decision making, patient decision aid, stable angina, cardiac catheter

\section{Introduction}

Coronary artery disease was the worldwide leading cause of death in 2002 (Finegold, Asaria, \& Francis, 2013). The number of deaths has increased from 5.74 million (12\%) in 1990 to 8.14 million (16.8\%) in 2013 (GBD, 2015). According to statistics in US in 2010 , the prevalence of coronary artery disease is $20 \%$ in populations above 65 -year-olds, $7 \%$ of $45-64$-year-olds, and $1.3 \%$ of $18-45$-year-olds. The incidence is higher in men than in women (CDC, 2011). According to the statistics of the Taiwan Ministry of Health and Welfare (2019), heart disease ranked in the second place in the top ten causes of death in 2018 in Taiwan and the number of deaths has increased $4.5 \%$ within a year. In addition, heart disease ranked second in the cause of death in the age above 45 -year-olds and coronary artery disease is one of the main reasons. The most common symptom of coronary artery disease is angina pectoris. Patients will complain about chest discomfort or breathing asthma. Stable angina pectoris can reduce the chance of heart attack and death by changing lifestyle and taking medication. Once angina pectoris affected the daily life, balloon dilatation and stent treatment can help patients relieve the symptoms and maintain a better quality of life. However, cardiac catheterization is an invasive treatment with side effects and risks. It is very important to help patients to think and evaluate carefully through SDM and determine the most appropriate treatment. Savitz (2020) identified 8300 patients $56 \%$ of patients received medication only, $28 \%$ received PCI, and $15 \%$ received CABG. Patients in low health literacy areas were less likely to receive CABG than were patients in high health literacy areas.

SDM (Shared decision making) is based on empirical medicine, cooperation between doctors and patients to 
discuss and select treatment options according to the medical profession and preferences of the patient. (Wendler, 2017) What's more, SDM is process of selecting medical diagnosis or treatment options that emphasizes mutual interaction and input of opinions to achieve the goal of medical decision-making between the medical team and patient through communication. The concept of medical-patient sharing decision-making was proposed by the President's Commission for the study of ethical problems in Medicine and Biomedical and Behavioral Research in the United States in 1982, with the aim of promoting mutual respect and communication between doctors and patients (Chou, Liang, Sun, \& Sun, 2017). Medical-patient sharing decisions include decision 3 "E": (1) Best Research Evidence; (2) Clinical Experts Experience; (3) Patients' Value and Expectation. (Wang, 2016) Physicians use the latest empirical research and personal experience to discuss and choose elements that meet their expectations with patients, which includes mutual participation of physician and patient, information that help patients explore and compare treatment options, evaluating patient values and considerations, sharing information between doctors and patients, establishing consensus between the two parties and reaching treatment decisions. (AHRQ, 2016; Elwyn et al., 2012; Chen et al., 2018) .The use of well-developed information provided through computer or DVD based, may enhance the decision-making process. A decision aid appears to be an effective method to support the surgeon in patient participation and involvement in the decision-making process(Pham et al., 2020)..

PDA (Patient Decision Aids) are tools specifically designed for patients to help patients understand the meaning of disease, clinical progress and treatment choices. In addition, patients can put forward their own considerations and expectations by using graphical explanations and interactive tools. With the help of the latest empirical medical evidence, doctors can make patients understand and make common medical decisions between physicians and patients to improve the efficiency of medical-patient communication (Ministry of Health and Welfare, 2016). Chang et al. (Chang, Chen, \& Kuo, 2019) found that the level of anxiety was reduced from $57.1 \%$ to $28.6 \%$ after using medical aids that effectively affected the choice of treatment, which helped to improve health awareness and promote medical-patient communication. The promotion experience of Chou et al. (Chou, et al., 2017) found that the two items that were quite satisfactory by patients were "assistance tools to help understand what is most important when facing various medical options" and "assistance tools to help make the most suitable Medical choice". Furthermore, the degree of anxiety was significantly reduced after the use of assistive tools $(2.7 \pm 0.7$ vs. $2.2 \pm 0.5, \mathrm{p}=<0.001)$, indicating that the patient's positive experience in using assistive tools that can reduce anxiety. Stacey (Stacey et al., 2014) systematically analyzed 34,444 cases in 115 studies. Compared with conventional care, SDM showed high degree of evidence that can improve the understanding of decision-making in individual cases and reduce the conflicts due to ignorance and unclear personal value; moderate degree of evidence showed that, comparing with conventional care, decision-making assistance can stimulate people to play a more active role in decision-making and improve awareness of risks; low degree of evidence showed that decision-making assistance can improve the consistency of options and value between doctors and patients. Therefore, the advantages are that the case has expectations that are more correct, improves decision-making participation, and increases patient knowledge. In addition, the factors affecting the success of medical decision-making should consider the previous knowledge and background of the case, the impact of medical options on the quality of life of the case. Moreover, it would be difficult for the case to discuss the medical decisions if the case is in a painful state (Joseph-Williams et al., 2019), Ryan (Ryan \& Vaughan, 2014) has shown that the proportions of performing surgery through discussion of medical decisions can be lowered by $20 \%$. The greatest scope for improvement may be within the areas of communication skills, interdisciplinary teamwork, and our patients what needed (Backman, Levine, Wenger, \& Harold, 2020).

\section{Method}

\subsection{Research Design}

This study was one-group pretest-posttest design.

\subsection{Participants}

The patients participated with this study are outpatients of cardiology during July 1 to Sep 30, 2019. Enroll conditions: Patients who have been diagnosed with coronary heart disease and have stable angina pectoris. Doctors recommend cardiac catheterization with balloon dilatation or stent placement. After physicians give oral instructions, patients provided informed consent to receive medical guidance and questionnaires. Conditions of exclusion: patients who have unstable angina pectoris, no need for balloon dilatation or placement of a stent without heart catheterization; unable to communicate in Taiwanese; unwilling to accept health education guidance and questionnaires. With $\mathrm{G}$ power software, two-tailed t-test, setting: $\alpha=.05, \beta=.8$, the number of receivable cases is 26 , the churn rate is $20 \%$, and 32 patients are expected. 


\subsection{Data Collection}

These data were collected from outpatients of cardiology who were diagnosed with coronary disease and stable angina pectoris, suggested to use cardiac catheters for balloon dilatation or stent treatment by doctor, in the Veterans General Hospital that located in the north of Taiwan.

First, posting the recruitment advertisements in the waiting area of the cardiology clinic and the cardiologist will explain the purpose and process of study to the patient who is suitable for the study. With the patient's verbal consent, the patient will be transferred to a quiet and private health education space. Secondly, one-on-one professional consultation with decision-making aid tool will be held for about 20-30 minutes, and complete the questionnaire of "Do I need to receive cardiac catheterization if I have stable angina?" In addition, cardiac medical staff will also complete the questionnaire after seeking consent.Enrollment of this study was performed after the study was reviewed and approved by the Institutional Review Board of LinKou Chang Gung Memorial Hospital (IRB No. 201900783 B0)

\subsection{Data Analysis}

The data were keyed in using Excel with an anonymized encoding process. The statistical software SPSS 20.0 (IBM SPSS Inc. Chicago Illinois) frequency, percentage, average score, sequence, Wilcoxon rank sum test, Chi-square test.

\subsection{Validity and Reliability}

The measure tools included:

(1) Patients: Using the public medical aids opinion questionnaire that was developed by the Taiwan Ministry of Health and Welfare, including 10 questions about the efforts made by medical staff and 3 questions about medical decision-making intension.

(2) Medical staff: Using the public medical aids opinion questionnaire that was developed by the Taiwan Ministry of Health and Welfare. Including 11 questions for recognition of how the SDM helps patients, 13 questions for promoting factors, 17 questions for obstacle factors (6 questions for system factors, 11 questions for patient factors).

(3) Scholars and experts of the SDM Promotion -Angina Pectoris Group from the Ministry of Health and Welfare, who use empirical methods to compile the questionnaire of "Do I need to undergo cardiac catheterization for stable angina?". It includes introduction, introduction of illness or health agenda, introduction of medical options, the method you currently prefer, the comparison of options, the options you care about and the degree of concern, understanding of the message, confirming treatment and relative information. The medical staff will be evaluated by intelligibility and professional suitability. If 4 points as total score, the average score of each paragraph is 3.72 , which resulted $93 \%$ and the average score is $85 \%$ in terms of help and practicality. The public will be evaluated by the intelligibility of each paragraph. If 4 points as total score, the average score of each paragraph is 3.28 , and score percentage is $82 \%$.

(4)Consistency of researchers: Four clinical staffs of cardiology are responsible for conducting a consensus meeting under the guidance and supervision of cardiology physician to confirm the process and methods and to practice the use of assistive tool descriptions. In the end, the opinions of four colleagues have to be consisted unanimous.

\section{Results}

\subsection{Sample Characteristics}

The numbers of patients that use SDM are 38. The majority of patients who use SDM is self $(89.5 \%), 71.1 \%$ people are male, the mean age range is $70-79$ years (47.4\%), most people's education level is college (44.7\%), and $52.6 \%$ of people make decision by themselves. Total 29 medical staff were included in this survey, $75.9 \%$ of medical staff were nurses and the mean age of work are 1-5 years (37.9\%). Demography of patient and Medical staff is shown as Table 1. 
Table 1. Demographic information of patient and medical staff

\begin{tabular}{|c|c|c|c|}
\hline Variance & & No. & $\%$ \\
\hline \multicolumn{4}{|l|}{ Patient $(n=38)$} \\
\hline \multirow[t]{2}{*}{ Identity } & Self & 34 & 89.5 \\
\hline & Relative & 4 & 10.5 \\
\hline \multirow[t]{2}{*}{ Sex } & Male & 27 & 71.1 \\
\hline & Female & 11 & 29.0 \\
\hline \multirow[t]{4}{*}{$\overline{\text { Age }}$} & $40-49$ years old & 4 & 10.5 \\
\hline & $50-59$ years old & 7 & 18.4 \\
\hline & $60-69$ years old & 9 & 23.7 \\
\hline & 70-79 years old & 18 & 47.4 \\
\hline \multirow[t]{6}{*}{ Education } & Elementary school & 3 & 7.9 \\
\hline & Junior high school & 6 & 15.8 \\
\hline & Senior high school & 7 & 18.4 \\
\hline & College & 17 & 44.7 \\
\hline & Master degree & 4 & 10.5 \\
\hline & Phd & 1 & 2.6 \\
\hline \multirow[t]{5}{*}{$\overline{\text { Attendant }}$} & Alone & 20 & 52.6 \\
\hline & Spouse & 7 & 18.4 \\
\hline & Offspring and their spouses & 6 & 15.8 \\
\hline & Other relatives & 4 & 10.5 \\
\hline & Others & 1 & 2.6 \\
\hline \multicolumn{4}{|l|}{ Medical staff $(n=29)$} \\
\hline \multirow[t]{2}{*}{ Occupation } & Doctor & 7 & 24.1 \\
\hline & Nurse & 22 & 75.9 \\
\hline \multirow[t]{6}{*}{ Job tenure (year) } & $1-5$ & 11 & 37.9 \\
\hline & $6-10$ & 6 & 20.7 \\
\hline & $11-15$ & 3 & 10.3 \\
\hline & $16-20$ & 3 & 10.3 \\
\hline & $21-25$ & 2 & 6.9 \\
\hline & Above 25 & 4 & 13.8 \\
\hline \multirow[t]{2}{*}{ Sex } & Male & 7 & 24.1 \\
\hline & Female & 22 & 75.9 \\
\hline
\end{tabular}

\subsection{Patient Identification for SDM}

The proportions of patients who answered "very much" to SDM recognition was from $53 \%$ to $63 \%$. The top three options were "Help you think about how much you can participate in this decision? (63\%)" "Helping you know that this decision depends on what matters to you the most? (58\%) "and" Help you organize your own thoughts on these decisions? (58\%) ". Data shows that more than half of the patients think that SDM helps them understand the case (Table 2). 
Table 2. Patient's recognition level about SDM (N=38)

\begin{tabular}{lll}
\hline Subject & Very much (\%) & Ranking \\
\hline Did SDM help you to know the involvement during decision-making? & 63 & 1 \\
\hline $\begin{array}{l}\text { Did SDM help you to know that the decision depends on thing, which matters } \\
\text { to you? }\end{array}$ & 58 \\
\hline Did SDM help you to organize the thoughts during decision-making? & 58 & 2 \\
\hline Did SDM help you to consider the most important pros and cons? & 55 & 3 \\
\hline Did SDM help you to realize the questions which you want to ask the doctor? & 55 & 3 \\
\hline Did SDM help you to share you main concern with doctor? & 55 & 3 \\
\hline Did SDM help you to make a better decision? & 53 & 4 \\
\hline Did SDM help you to consider the pros and cons? & 53 & 4 \\
\hline Did SDM help you to realize that you have to make decision? & 53 & 4 \\
\hline Did SDM help you to schedule the follow-up with doctor? & 53 & 4 \\
\hline
\end{tabular}

The $82 \%-93 \%$ patients recognize the efforts made by the medical staff, which is "a lot", which followed by "How much effort did the medical staff make while listen to the things you care about most? (93\%)", "How much effort did the medical staff make to help you understand your health issues? (89\%)", "How much effort did the medical staff take the things you care the most in to consideration while choose the next step? $(82 \%)$ ", which has only 7\% people choose "Some" in questionnaire. It shows that medical staff should pay more attention to what patients care about when they select patients (Table 3 ).

Table 3. Patient's recognition about the effort of medical staff $(\mathrm{N}=38)$

\begin{tabular}{lcc}
\hline Subject & A lot (\%) & Ranking \\
\hline $\begin{array}{l}\text { What is the level of effort of medical staff while they hear health problem that } \\
\text { matters to you the most? }\end{array}$ & 1 \\
\hline $\begin{array}{l}\text { What is the level of effort of medical staff while they help you to realize your } \\
\text { health problem? }\end{array}$ & 29 \\
$\begin{array}{l}\text { What is the level of effort of medical staff while they take things that matters to } \\
\text { you in to consideration? }\end{array}$ & 32 \\
\hline
\end{tabular}

\subsection{The Impact for SDM on Decision-Making of Patient}

Before using SDM, 21\% of patients choose "unclear" and decrease 18\% after using SDM. The proportions of people who choose "medicine + surgery" increased 32\%, from 34\% to 66\%. The Chi-square test was used to analyze the patient decision sharing $\left(\mathrm{X}^{2}=14.26, \mathrm{p}=.007\right)$. The result shows that there is a statistically significant difference in the patient's decision after sharing the decision. "I have stable angina and need to undergo cardiac catheterization." Decision sharing does have a positive effect on patients (Table 4). Half of 38 patients who did SDM had completed cardiac catheterization after 4 months.

Table 4. Comparison of patient before and after using SDM $(\mathrm{N}=38)$

\begin{tabular}{llll}
\hline Subject & Before SDM (\%) & After SDM (\%) & P-value \\
\hline Unclear & 21 & 3 & $0.007 *$ \\
\hline Only medication & 45 & 32 & \\
\hline Medication +surgery & 34 & 66 &
\end{tabular}

Using: Chi-square test *p-value $<0.05$ 


\subsection{SDM Associated Factor of Promotion}

The top three promoting factors among medical staff for SDM implementation are "After patient understand the disease and treatment, they are ready for consultation (86\%)", "Improve doctor-patient communication efficiency (69\%)", and "Improve doctor-patient relationship "(69\%)", "Provide hard copy (69\%)", "Patient has attendant during consultation (69\%) ", and" Patients trust me (69\%)". The result shows that hard copy of PDA can improve doctor-patient communication efficiency and the doctor-patient relationship at the same time Table 5).

Table 5. Facilitating factors for medical staff to promote SDM (multiple choice) $(\mathrm{N}=29)$

\begin{tabular}{lcc}
\hline \multicolumn{1}{c}{ Subject } & $\%$ & Ranking \\
\hline After patient understand the disease and treatment, they are ready for consultation & 86 & 1 \\
\hline Provide hard copy & 69 & 2 \\
\hline Patient has attendant during consultation & 69 & 2 \\
\hline Patient trust me & 69 & 2 \\
\hline Improve doctor-patient relationship & 69 & 2 \\
\hline Improve doctor-patient communication efficiency & 52 & 6 \\
\hline Demand of national policy & 48 & 7 \\
\hline Convenient decision aid tool is available & 45 & 8 \\
\hline Increase the participation of patient during medical care & 41 & 9 \\
\hline Wish to improve clinical care & 38 & 10 \\
\hline Wish to decrease cost of medical care & 34 & 11 \\
\hline Patient-centered care & 24 & 12 \\
\hline Others & 3 & 13 \\
\hline
\end{tabular}

\subsection{Obstacle Factors for Pushing SDM}

Medical staff believes that the relevant factors of "System-related difficulties" are "Insufficient time to talk with patient" (41\%), "Patient takes family factors as prior consideration while choosing treatment (34\%)", and "Patient prefer treatment instead of consultation (28\%)". "Patient-related difficulties" are "Patient hesitate (69\%)", "Patient couldn't listen to the medical staff because of the worries (41\%)", "Patient does not understand the information I provide (38\%)". The traditional medical communication model mainly based on the professional opinions of physicians. However, due to changes in policies and implementations, patients need more time to learn and accept the new model of sharing decision making between health professionals and patients. Besides, there is not enough time for discussion because of limited clinical time. It is common for patient to hesitate to make an immediate decision in clinical practice. The hard copy of decision-making tools allows the patient to bring it back to read, think and discuss with family members before the next visit. After discussing and asking key questions, it can help communication between doctors and patients, and then make decisions that can decrease the difficulty of medical staff in using SDM (Table 6).

Table 6. Obstacles to medical staff's promotion of SDM (multiple choice) $(\mathrm{N}=29)$

\begin{tabular}{lll}
\hline Subject & $\%$ & Ranking \\
\hline System-related difficulties & 41 & 1 \\
\hline Insufficient time to talk with patient & 34 & 2 \\
\hline Patient takes family factors as prior consideration while choosing treatment & 28 & 3 \\
\hline Patient prefer treatment instead of consultation & 26 & 4 \\
\hline I face problems while providing treatment for patient & 0 & 6 \\
\hline Others & & 6 \\
\hline
\end{tabular}




\begin{tabular}{lll}
\hline $\begin{array}{l}\text { During the first consultation, I didn't have enough information to assist patients to } \\
\text { make medical decision }\end{array}$ & 7 \\
\hline Patient-related difficulties & 69 & 1 \\
\hline Patient hesitate & 41 & 2 \\
\hline Patient couldn't listen to the medical staff because of the worries & 38 & 3 \\
\hline Patient don't understand the information I provide & 21 & 4 \\
\hline Patient has misunderstanding with the disease and treatment & 21 & 4 \\
\hline Patient has hard time to accept the fact that he has disease & 17 & 6 \\
\hline Can't discuss with patient because of too many information which patient brings & 17 & 6 \\
\hline Uncertain about the treatment which patient requires is benefit or not & 14 & 8 \\
\hline Patient didn't want to use SDM & 10 & 9 \\
\hline Patient wants to get involve with more treatment decision & 10 & 9 \\
\hline Patient refuses the treatment that I recommend & 0 & 11 \\
\hline Others & & 7 \\
\hline
\end{tabular}

\subsection{Recognition of Medical Staff With SDM}

After analyzing 29 medical staffs, the top four options of SDM recognition are "very many" among the decision tools to help patients identify the items in order of "Did SDM help with the fellow-up consultation? (41\%)", "Did SDM help my patient to be ready for the follow-ups consult? (38\%)", "Did SDM help me to thoroughly understand the question that matters to my patient? (38\%)"," Did SDM help me to plan process of consult according to my patient's preference? (38\%)" Result shows that decision aids tool can help medical staff not only understand the patient's thought but also improve communication and follow-up consultations (Table 7).

Table 7. Recognition of medical staff with SDM (N=29)

\begin{tabular}{lll}
\hline Subject & Very many (\%) & Ranking \\
\hline Did SDM help with the fellow-up consultation? & 41 & 1 \\
\hline Did SDM help my patient to be ready for the follow-ups consult? & 38 & 2 \\
\hline $\begin{array}{l}\text { Did SDM help me to thoroughly understand the question that matters to my } \\
\text { patient? }\end{array}$ & 28 \\
\hline $\begin{array}{l}\text { Did SDM help me to plan process of consult according to my patient's } \\
\text { preference? }\end{array}$ & 28 \\
\hline $\begin{array}{l}\text { Did SDM help my patient thoroughly understand the pros and cons of } \\
\text { treatment? }\end{array}$ & 34 \\
\hline $\begin{array}{l}\text { Did SDM help my patient to understand the importance of the pros and cons of } \\
\text { treatment? }\end{array}$ & 34 \\
\hline Did SDM help me to improve the quality of fellow-up consultation? & 5 \\
\hline Did SDM help my patient to participate the process following their own will? & 31 \\
\hline Did SDM help my patient to make better decision? & 31 \\
\hline Did SDM help to improve my relationship with the patient? & 28 \\
\hline Did SDM help me to improve the time of fellow-up consultation? & 8 \\
\hline
\end{tabular}

\subsection{Patients' Anxiety in Medical Decision-Making After SDM}

The assistance of decision-making tool for patients can be rated from 1 to 5 points, with an average score of 4.2 points. "How much anxiety do you have while face current medical problems before using SDM?" scores 3.5 
points. "How much anxiety do you have while face current medical problems after using SDM" is 2.1 points, which shows that the anxiety level reduced 1.4 points after health education. The anxiety level of patients before and after sharing decision was tested by Wilcoxon rank sum test (the $\mathrm{z}$ value was $4.6591, \mathrm{p}<0.0001$ ), which means that the patient's level of anxiety statistically decreased after using SDM

\section{Discussion}

The average age in this study were above 45 years old, with $71.1 \%$ of patients are men whose number is greater than female, which is similar to the statistics of coronary artery disease in the United States (CDC, 2011). In this study, after using SDM, the patient's willingness to consider cardiac catheterization increased from $34 \%$ to $66 \%$, a $34 \%$ of increase, with the actual implementation rate 50\%. Ryan and others reduced the percentages of performing surgery by 20\% through discussion with SDM (Ryan \& Vaughan, 2014 ) Shen and other scholars (Shen, Chao, \& Chen, 2019) increased willingness of treating spinal fractures from $68.1 \%$ to $97.9 \%$, with an increase of $29.8 \%$, which indicates that the use of SDM has the benefit of increasing the willingness to accept treatment. The top three recognitions of patients with decision aids in this study are "Help you think about how much you can participate in this decision? (63\%)", "Helping you know that this decision depends on what matters to you the most? (58\%)" and "Help you organize your own thoughts on these decisions? (58\%)". The $82 \%-93 \%$ patients recognize the efforts made by the medical staff, which is "a lot", which followed by " How much effort did the medical staff make while listen to the things you care about most?" (93\%) "," How much effort did the medical staff make to help you understand your health issues? (89\%) "," How much effort did the medical staff take the things you care the most in to consideration while choose the next step? (82\%) ", which is similar to the study of Yang's research (Yang, Chung, Chou, Yeh, \& Chen, 2019) that $90 \%$ of patients agree that the decision-making process was helpful. The highest score in survey (4.1 points) of Chang et al. (2019) are "Did SDM help you to consider the pros and cons?" and "Did SDM help you to realize the questions which you want to ask the doctor?" The promotion experience of scholars such as Chou (Chou, et al, 2017) reveals the two things that were quite satisfactory: "Assistance tools to help understand what is most important when facing various medical options" and "Assistance tools to help make the most suitable medical choice". Stacey found (Stacey et al., 2014) that medical-patient SDM can improve individual understanding of decision-making and reduce decision conflicts related to unknowing and unclear personal values. Individuals can have correct expectations, improve decision-making, participate and increase patient knowledge. Therefore, doctor-patient sharing decision mode shows a positive relationship in patient's decision-making, and it helps mutual trust relationship of doctor and patient.

In addition, individual knowledge background is one of factors that influence the success of medical decision-making. If patient's emotion is stable, it is easy to discuss with them. (Joseph-Williams et al., 2019). In this case, $57.8 \%$ of the patients have college or higher degree, and are easier to accept SDM during the angina pectoris stage.

While $86 \%$ of medical staffs agreed to promote SDM to " After patient understand the disease and treatment, they are ready for consultation ", $69 \%$ of medical staffs agreed to " Improve doctor-patient communication efficiency ", " Improve doctor-patient relationship ", " Provide hard copy " " Patient has attendant during consultation " and "Patients trust me". The result showed that the hard copy of PDA can promote the efficiency of medical-patient communication and improve the relationship between doctors and patients. Chang et al. (Chang, et al., 2019) surveyed the use of decision aids among medical staff. The highest score (4.8 points) appeared in "patients think about the pros and cons of each option", "patients can identify questions they want to ask medical staff" and "improve health recognition of patient". Moreover, the highest degree of recognition (4.8 points) in projects such as "promoting the relationship between doctors and patients" and "willing to share this decision-making process with other medical staff" indicated that PDA could increase medical service satisfaction.

Among the obstacle factors, "insufficient time to talk with patient" (41\%) believed to be the biggest obstacle in systemic problems. This study of SDM would take each patient 20-30 minutes to complete the process of SDM, which would shorten the clinical time in the outpatient department. The discussion time with patient was insufficient to reflect truly the dilemma of the clinical staff. Therefore, the hospital should recruit sufficient labor to promote the government's policy of SDM. Another $69 \%$ of medical staff believed that "patient hesitate" is the biggest problem among patients. While traditional medical decision-making was based on professional knowledge of physician, SDM emphasized doctor-patient sharing decision-making that means patients should learn to choose and decide by themselves. Due to the change of medical decision model, the government should continue to introduce and educate the meaning and method of SDM. Medical staff and patients must learn and accept the new medical decision-making process. 


\section{Conclusion}

SDM is the discussions with the latest empirical research and personal professional between patients and doctor. The process includes participation of physician and patient, information that help patients explore and compare more treatment options, evaluating patient values and considerations, sharing information between doctors and patients, establishing common opinion and reaching a treatment decision. In this study, we found that both medical staff and patients have positive feedback and statistically significant differences in affecting the patient's medical willingness and reducing patient anxiety in SDM. However, the lack of discussion time and hesitation of patient are two biggest obstacles while promote SDM.

\section{Study Limitation and Recommendation}

The limitation of this study is single-group measurement that indicates the lack of comparison of control group before and after measurement. In the future, we can conduct experiments with a randomized controlled trial design to confirm the benefits of SDM as a policy reference for promotion in the future. SDM has received not only positive feedback and affirmation from patients but also sense of professional accomplishment from nursing colleagues who is in charge of health education. Because medical staff is busy with work, the cognition and acceptance still need to improve. The government still needs to promote SDM, stimulates and encourages the participation of medical institutions and continues to demonstrate the effectiveness of promotion in order to increase the acceptance of medical staff.

\section{References}

AHRQ. (2016). The share approach—health literacy and shared decision making: a reference guide for health care providers. Retrieved from http://www.ahrq.gov/professionals/education/curriculum-tools/shareddecisionmaking/tools/tool-4/index.htm 1

Backman, W. D., Levine, S. A., Wenger, N. K., \& Harold, J. G. (2020). Shared decision-making for older adults with cardiovascular disease. Clinical Cardiology, 43(2), 196-204. https://doi.org/10.1002/clc.23267

CDC. (2011). Prevalence of coronary heart disease--United States, 2006-2010. MMWR Morb Mortal Wkly Rep, 60(40), 1377-1381.

Chang, T. T., Chen, Y. C., \& Kuo, S. C. (2019). Applying a Patient Decision Aid to Facilitate Decision Making in Women with Pelvic Organ Prolapse. VGH Nursing, 36(4), 353-360. https://doi.org/10.6142/vghn.201912_36(4).0003

Chen, S., Chen, Y., Peng, J., Yang, S., Fang, Q., Zhou, H., \& Tang, W. (2018). Sharing decision Making - The Three Talk model as an example. Clinical Medicine, 81(6), 342-347. https://doi.org/10.6666/ClinMed.201806_81(6).0063

Chou, C. Y., Liang, H. W., Sun, P. C., \& Sun, J. S. (2017). The practical experience of introducing shared decision making for patients with coronary artery disease in a medical center. Journal of Healthcare Quality, $7(1), 52-63$.

Elwyn, G., Frosch, D., Thomson, R., Joseph-Williams, N., Lloyd, A., Kinnersley, P., ... Barry, M. (2012). Shared decision making: a model for clinical practice. $J$ Gen Intern Med, 27(10), 1361-1367. https://doi.org/10.1007/s11606-012-2077-6

Finegold, J. A., Asaria, P., \& Francis, D. P. (2013). Mortality from ischaemic heart disease by country, region, and age: statistics from World Health Organisation and United Nations. Int J Cardiol, 168(2), 934-945. https://doi.org/10.1016/j.jicard.2012.10.046

GBD 2013 Mortality and Causes of Death. (2015). Global, regional, and national age-sex specific all-cause and cause-specific mortality for 240 causes of death, 1990-2013: a systematic analysis for the Global Burden of Disease Study 2013. Lancet, 385(9963), 117-171. https://doi.org/10.1016/s0140-6736(14)61682-2

Joseph-Williams, N., Williams, D., Wood, F., Lloyd, A., Brain, K., Thomas, N., ... Edwards, A. (2019). A descriptive model of shared decision making derived from routine implementation in clinical practice ('Implement-SDM'): Qualitative study. Patient Educ Couns, 102(10), 1774-1785. https://doi.org/10.1016/j.pec.2019.07.016

Ministry of Health and Welfare. (2016. June 1). Introduction of SDM and PDA. Retrieved from https://sdm.patientsafety.mohw.gov.tw/Public/Detail?sn=9\&id=1064

Ministry of Health and Welfare. (2019, June 21). 2018 death statistics. Retrieved from 
https://www.mohw.gov.tw/cp-16-48057-1.html

Pham, C., Lizarondo, L., Karnon, J., Aromataris, E., Munn, Z., Gibb, C., ... Maddern, G. (2020). Strategies for implementing shared decision making in elective surgery by health care practitioners: A systematic review. Journal of Evaluation in Clinical Practice, 26(2), 582-601. https://doi.org/10.1111/jep.13282

Ryan, P., \& Vaughan, D. (2014). Confronting evidence: individualised care and the case for shared decision-making. Ir Med J, 107(10), 331-332.

Savitz, S. T., Bailey, S. C., Dusetzina, S. B., Jones, W. S., Trogdon, J. G., \& Stearns, S. C. (2020). Treatment selection and medication adherence for stable angina: The role of area-based health literacy. Journal of Evaluation in Clinical Practice. https://doi.org/10.1111/jep.13341

Shen, K. F., Chao, C. L., \& Chen, Y. C. (2019). Using Medical Disease Shared Decision-Making to Improve Recognition Accuracy of Spinal Compression Fractures. The Kaohsiung Journal of Nursing, 36(2), 28-40. https://doi.org/10.6692/KJN.201908_36(2).0003

Stacey, D., Legare, F., Col, N. F., Bennett, C. L., Barry, M. J., Eden, K. B., ... Wu, J. H. (2014). Decision aids for people facing health treatment or screening decisions. Cochrane Database Syst Rev, (1), Cd001431. https://doi.org/10.1002/14651858.CD001431.pub4

Wang, Y. G. (2016). Sharing Decision Making Policy - PDA implementation in clinical practice. Journal of Healthcare Quality, 10(4), 15-24.

Wendler, D. (2017). The Theory and Practice of Surrogate Decision-Making. Hastings Cent Rep, 47(1), 29-31. https://doi.org/10.1002/hast.671

Yang, J. Y., Chung, H. C., Chou, S. Y., Yeh, T. F., \& Chen, C. L.(2019). Effect of Shared Decision-Making on Patient Anxiety and Treatment Choice. Cheng Ching Medical Journal, 15(3), 16-33.

\section{Copyrights}

Copyright for this article is retained by the author(s), with first publication rights granted to the journal.

This is an open-access article distributed under the terms and conditions of the Creative Commons Attribution license (http://creativecommons.org/licenses/by/4.0/). 